\title{
Low Incidence of Germline and Somatic Alterations in the E-Cadherin Gene in Lobular Breast Carcinoma
}

\author{
R.K. Schmutzler ${ }^{1}$, \\ P. Derakhshandeh-Peykar ${ }^{2}$, D. Freihoff ${ }^{1}$, \\ O. Brandau ${ }^{2}$ and A. Meindl ${ }^{2}$ \\ ${ }^{1}$ Department of Ob/Gyn, University Medical \\ Center Bonn, Germany \\ ${ }^{2}$ Department of Medical Genetics at the \\ LMU, Munich, Germany
}

Germline mutations of E-cadherin have been identified in families with gastric cancer. Moreover, E-cadherin has been shown to be inactivated in the majority of human invasive lobular breast cancers. E-cadherin is a tumor suppressor gene located in 16q22.1, a region which is frequently deleted in a variety of tumors. We therefore analysed 15 families with lobular breast cancer or breast and gastric cancer for germline mutations and 20 sporadic lobular breast carcinomas for somatic mutations in the Ecadherin gene. Screening of the lobular breast cancer families revealed two germline mutations of the missense type (A592T, P692L). One of these mutations (A592T) has previously been identified in a sporadic papillary thyroid tumor. No germline mutations were found in breast and gastric cancer associated families. Only 2 mutations could be identified in the tumor panel. Both were of the frameshift type and associated with $\mathrm{LOH}$ causing inactivation of E-cadherin. We here report for the first time germline mutations in the E-cadherin gene in families with lobular breast carcinomas. In addition, the frequency of E-cadherin mutations in our panel of lobular breast carcinomas is lower than published in former studies.

Supported by the Deutsche Krebshilfe. 


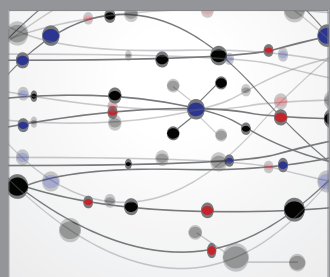

The Scientific World Journal
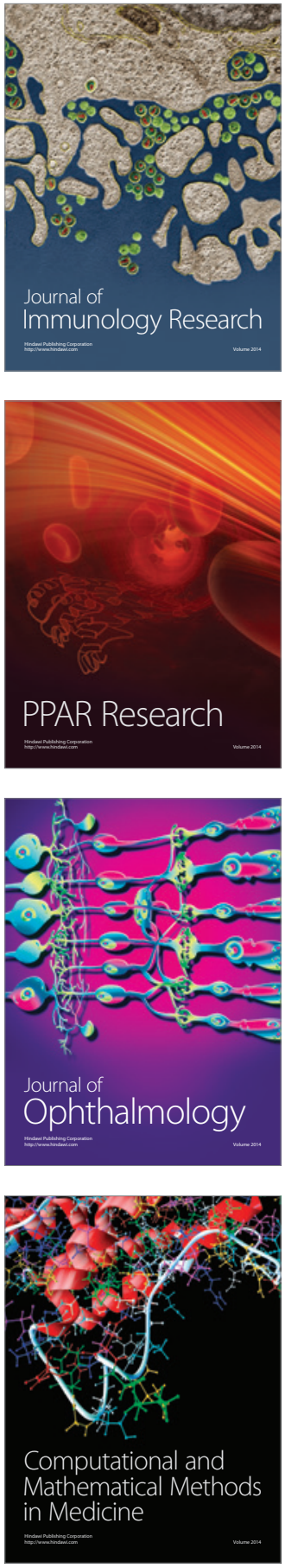

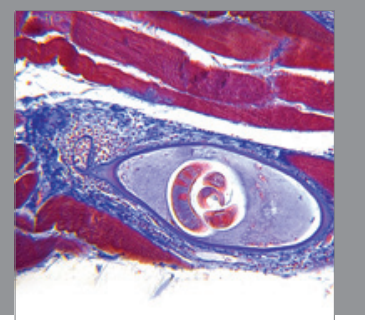

Gastroenterology

Research and Practice
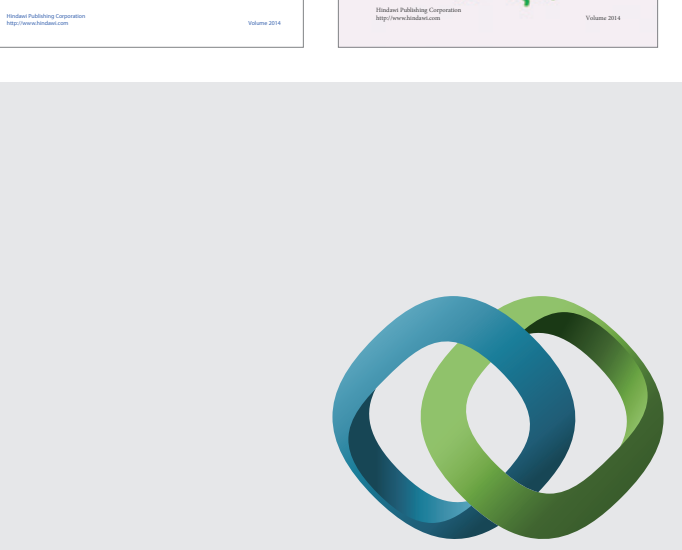

\section{Hindawi}

Submit your manuscripts at

http://www.hindawi.com
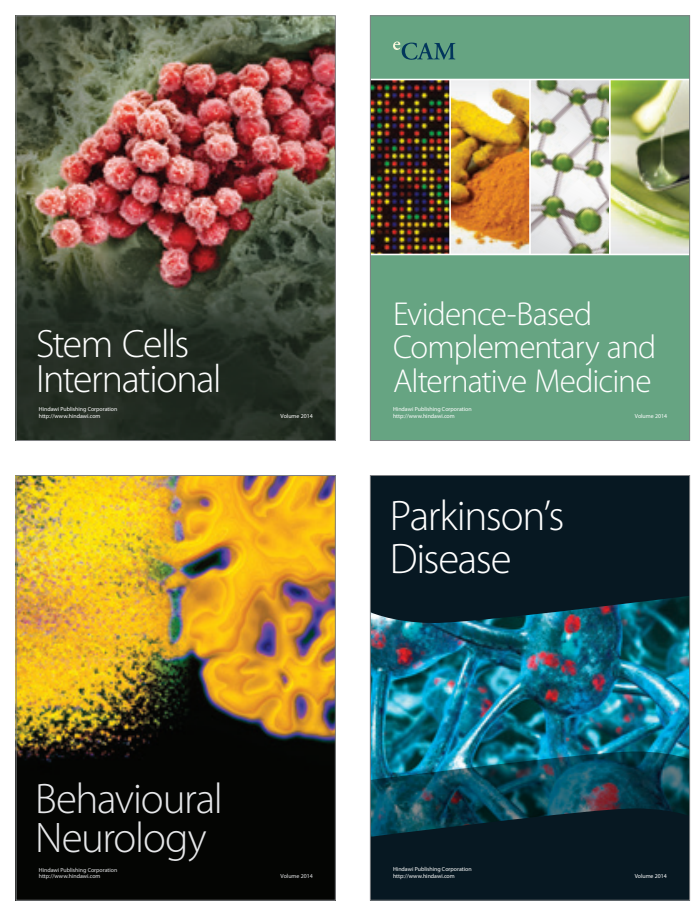

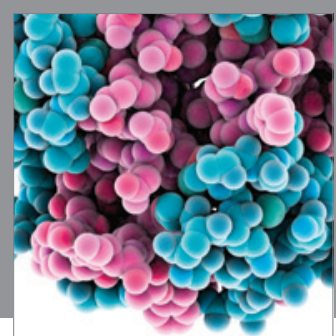

Journal of
Diabetes Research

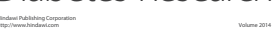

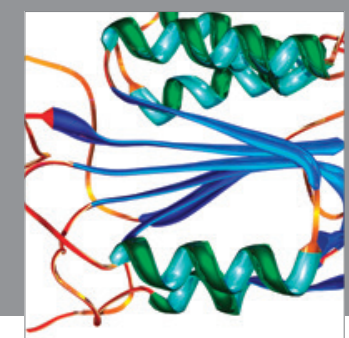

Disease Markers
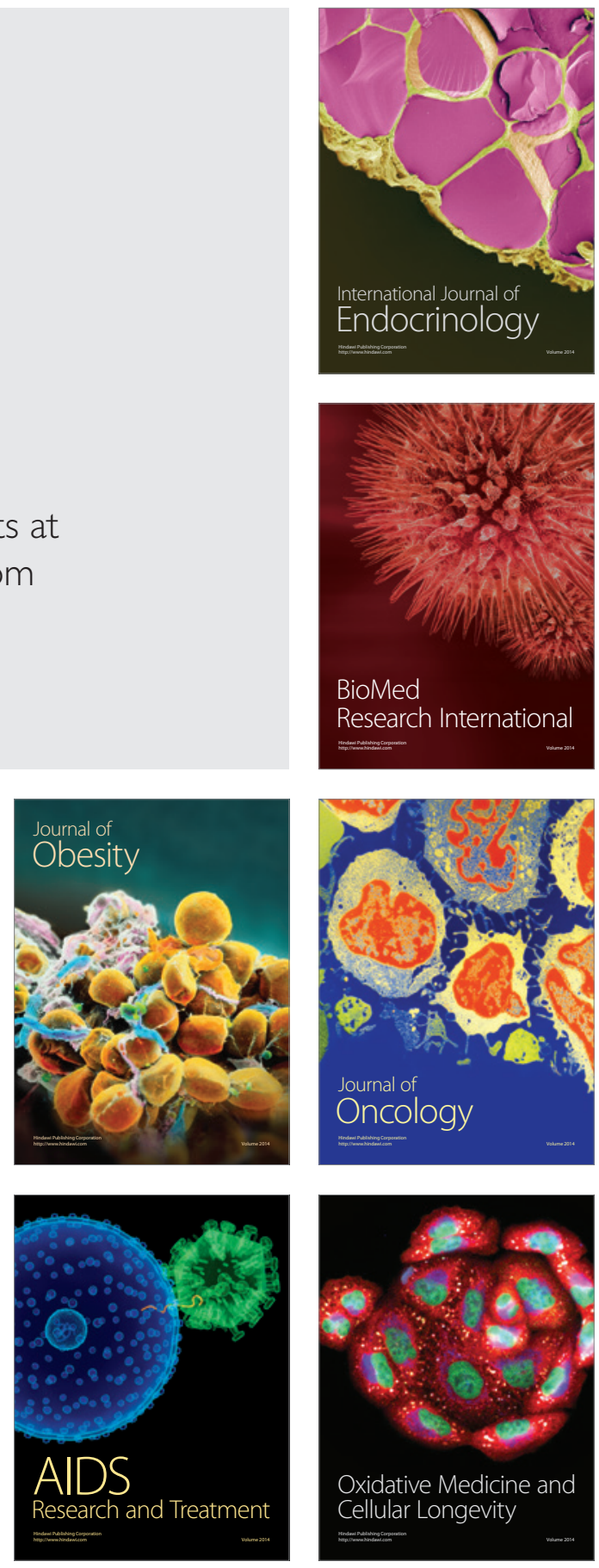